\title{
Expression of Mo3e Antigen by Cultured Human Umbilical Vein Endothelial Cells (HUVEC) Stimulated by Phorbol Myristate Acetate (PMA) and Related Pharmacological Inducers of Protein Kinase C
}

\author{
R. Douglas Trochelman, ${ }^{*}$ Stephen J. Weiss, ${ }^{*}$ Sandra Regiani, ${ }^{*}$ \\ DAVID Y. LIU, $\dagger$ AND ROBERT F. TODD III*,l \\ *Simpson Memorial Research Institute, Department of Internal Medicine, Division of Hematology/ \\ Oncology, Universily of Michigan Medical School, Ann Arbor, Michigan 48109, and \\ †Cetus Corporation, Department of Immunology, Palo Alto, California 94303
}

Received July 23, 1987; accepted October 7, 1987

Mo3e is a protease-sensitive membrane antigen (p75,50) selectively expressed by human monocytic cells (monocytes and U-937 cells) stimulated in vitro by exposure to a variety of activating factors, including phorbol diester compounds, bacterial lipopolysaccharide (LPS), and muramyl dipeptide (MDP) (R. F. Todd et al., J. Immunol. 135, 3869, 1985). Here we report that primary and multiply-passaged cultures of HUVEC also express the Mo3e determinant after stimulation by phorbol myristate acetate (PMA) and related inducers of protein kinase $C$. As measured in a radioimmunoassay of anti-Mo3e antibody binding to monolayer cultures of HUVEC, unstimulated cells bore little if any Mo3e. $\Lambda$ fter culture for 4-120 hr in medium containing PMA, $4 \beta$-phorbol dibutyrate, $4 \beta$-phorbol didecanoate, or mezerein (each at a concentration of $81 \mathrm{n} M)$, or 1-oleoyl-2-acetoyl-sn-3-glycerol ( $1 \mathrm{~m} M)$, HUVEC were found to selectively express the Mo3e determinant. The magnitude of expression was dependent upon the concentration of the stimulus, maximal by $24 \mathrm{hr}$, and inhibited by cycloheximide. The combination of PMA and the calcium ionophore, ionomycin, had an additive or synergistic effect on HUVEC Mo3e expression. The biologically inactive phorbol compounds $4 \beta$-phorbol and $4 \alpha$ phorbol didecanoate failed to stimulate Mo3e expression. Also inactive as inducers of HUVEC Mo3e expression were crude lymphokine and monokine supernatants, recombinant human lymphokines (interferon- $\gamma$ and interleukin-2), recombinant human monokines (interleukin-1 and tumor necrosis factor), bacterial cell wall products including LPS and MDP, pharmacologic agents that increase intracellular cyclic adenosine monophosphate (prostaglandin $E_{2}$, cholera toxin, theophylline, isoproterenol and isobutylmethylxanthine), lectins (Con A and PHA), and heparin. These results indicate that Mo3e is an inducible plasma membrane antigen of not only mononuclear phagocytes but also cultured HUVEC. 1988 Academic Press, Inc.

\section{INTRODUCTION}

Cells of the mononuclear phagocyte system and endothelial cells display a number of similar physiological characteristics that include the capacity to ingest soluble and particulate matter (pinocytosis and phagocytosis, respectively) $(1,2)$, to present anti-

\footnotetext{
' To whom correspondence should be addressed at the Simpson Memorial Research Institute, $102 \mathrm{Ob}-$ servatory Drive, Ann Arbor, MI 48109.
} 
genic material to $\mathrm{T}$ lymphocytes in association with plasma membrane Ia (class II) histocompatability determinants (3-6), and to synthesize and secrete certain soluble inflammatory mediators such as interleukin- 1 (IL-1) ${ }^{2}(7-9)$. The performance of these and other functional activities by mononuclear phagocytes and endothelial cells is up-regulated by exposure to a variety of inflammatory activating factors in vitro or in vivo $(1,5,8,9)$. The physiolngic "activation" of macrophages and endothelial cells is often manifest by changes in morphology, metabolic activity, and plasma membrane composition. For example, exposure of human monocytes or human umbilical vein endothelial cells (HUVEC) to interferon- $\gamma$ (IFN- $\gamma$ ) in vitro stimulates the surface expression of Ia determinants (10-14). Other changes in plasma membrane phenotype that occur as a consequence of activation include the enhanced surface expression of $\mathrm{Fc}$ receptors by interferon-stimulated human monocytes $(15,16)$ or by endothelial cells after cytomegalovirus (CMV) infection (17), ICAM-1 (a molecule promoting cellular adhesion) by U-937 monoblasts stimulated with phorbol myristate acetate (PMA) (18) and by HUVEC exposed to IL-1, IFN- $\gamma$ or tumor necrosis factor (TNF) $(18,19)$, and membrane-bound tissue factor (procoagulant activity) by human monocytes $(20,21)$ and HUVEC cultured in medium containing TNF (22, $23)$, IL-1 (24-27), or bacterial lipopolysaccharide (LPS) $(24,25,27)$.

The application of hybridoma-generated monoclonal antibody technology has led to the identification of additional activation associated plasma membrane determinants expressed by mononuclear phagocytes and/or endothelial cells. In the mononuclear phagocyte system these include the acquired expression of the AcM.1 (28), Asialo GMI (29), 7/4 (30), MAA-1 (31), and MA158.2 $(32,33)$ antigenic determinants by murine macrophages activated in vivo (by $B C G$ or Cornyebacterium parvum inoculation) or in vitro (by lymphokines), and the expression of the A1-3 $(34,35)$ and Mo3e(36) antigens by human mononuclear phagocytes exposed to soluble-activating factors (LPS, PMA, IFN- $\gamma$ ) in vitro. Likewise, Pober and his colleagues have demonstrated the expression of $\mathrm{H} 4 / 18$ by HUVEC activated in vitro by exposure to IL-1, TNF, and LPS $(37,38)$.

With the goal of further characterizing the plasma membrane consequences of human mononuclear phagocyte activation, we previously generated a murine monoclonal antibody specific for an antigen, Mo3e (p75, 50), expressed by human monocytes stimulated in vitro by exposure to soluble-activating factors including LPS, PMA, and MDP (36). In this report, we have demonstrated that surface Mo3e expression is also selectively acquired hy HUVFC cultured in medium containing PMA and certain other compounds known to stimulate the activation of protein kinase $C$.

\footnotetext{
${ }^{2}$ Abbreviations used: BSA, bovine serum albumin; CMV, cytomegalovirus; Con A, concanavalin A; cpm, counts per minute; DPBS, Dulbecco's phosphate-buffered saline; ECGS, endothelial cell growth supplement; HUVEC, human umbilical vein endothelial cells; IL-1, interleukin-1; IFN- $\gamma$, interferon- $\gamma$; LPS, Escherichia coli lipopolysaccharide; I.PS-MCM, lipopolysaccharide-stimulated monocyte-conditioned medium; MDP, muramyl dipeptide ( $N$-acetylmuramyl-L-alanyl-D-isoglutamine); MEZ, mezerein; NGS, normal goat serum; NP-40, Nonidet P-40 detergent; OAG, L- $\alpha$-1-oleoyl-2-acetoyl-sn-3-glycerol; PBMC, peripheral blood mononuclear cells; PBS, phosphate-buffered saline; PHA, phytohemagglutinin; PHALCM, phytohemagglutinin-stimulated lymphocyte-conditioned medium; $4 \beta \mathrm{PDB}, 4 \beta$-phorbol 12,13-dibutyrate; $4 \alpha \mathrm{PDD}, 4 \alpha$-phorbol 12,13-didecanoate; $4 \beta \mathrm{PDD}, 4 \beta$-phorbol 12,13-didecanoate; PMA, phorbol myristate acetate (4 $\beta$-phorbol 12-myristate-13-acetate); RIA, radioimmunoassay; TNF, tumor necrosis factor $\alpha ; 1640$-AS, RPMI 1640 medium supplemented with $10 \%$ autologous serum; MIF, migration inhibitory factor.
} 


\section{MATERIALS AND METHODS}

Media and reagents. The following media and tissue culture additives were purchased from GIBCO Laboratories (Grand Island, NY): Medium 199 with $25 \mathrm{mM}$ Hepes buffer, Hanks' salts and L-glutamine (380-2350); $200 \mathrm{~m} M$ L-glutamine (3205030); penicillin-streptomycin solution (600-570); 1-X trypsin-EDTA (610-5300); RPMI 1640 (320-1875). The following reagents were purchased from Sigma Chemi-

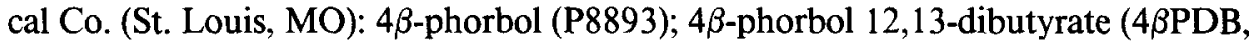

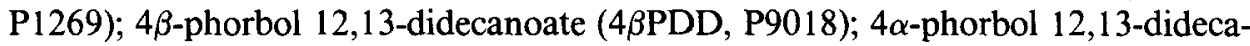
noate ( $4 \alpha \mathrm{PDD}, \mathrm{P} 8014)$; $4 \beta$-phorbol 12-myristate 13-acetate (PMA, P8139); dimethyl sulfoxide (DMSO, D5879); Escherichia coli LPS (L2755); phytohemagglutinin (PHA, L8504); cholera toxin (C3012); 3-isobutyl-1-methylxanthine (IBMX; 15879); concanavalin A (Con A, C2010); cycloheximide (C6255); theophylline (T1633); isoproterenol (I5627); bovine serum albumin (BSA, A4503); diaminobenzidine (DAB, D8001); and Histopaque (1077-1). Mezerein (MEZ, M4600) was purchased from LC Services Corp. (Woburn, MA). L- $\alpha$-1-Oleoyl-2-acetoyl-sn-3 glycerol (OAG, 800100) was purchased from Avanti Polar Lipids, Inc. (Birmingham, AL). Ionomycin from Streptomycin conglobatus (407952) was purchased from Calbiochem (San Diego, CA). Ultrapure IL-1 (GUPI-1) was purchased from Genzyme (Boston, MA). Porcine heparin (1000 u/ml, 2440-41) was purchased from Elkins-Sinn, Inc. (Cherry Hill, NJ). Recombinant interleukin-2 (IL-2, CPL 1A-012) and recombinant TNF- $\alpha$ (Lot NP102) were gifts of the Cetus Corp. (Emeryville, CA). Recombinant human IFN- $\gamma$ (Ro 23-4400) was a gift of Dr. Sidney Pestka, Roche Institute of Molecular Biology (Nutlcy, NJ). Hanks' balanced salts solution without phenol red, calcium, or magnesium (55-02577) was purchased from Hazleton Research Products, Inc. (Lenexa, KA). Endothelial cell growth supplement (ECGS) was purchased from Collaborative Research Products (Cambridge, MA). Lactated Ringer's solution was purchased from Abbott (North Chicago, IL). Type I collagenase was purchased from Worthington Biochemical (Freehold, NJ). Amphotericin B was purchased from E. R. Squibb \& Sons, (Princeton, NJ). NP-40 was purchased from Particle Data Laboratories, Ltd. (Elmhurst, IL). Phosphate-buffered formalin solution (10\%, SO-F-100) was purchased from Fisher Scientific (Fairlawn, NJ).

PMA, $4 \beta \mathrm{PDB}, 4 \beta \mathrm{PDD}, 4 \alpha \mathrm{PDD}, 4 \beta$-phorbol, MEZ, and OAG were initially diluted in DMSO to make stock solutions of $1 \mathrm{mg} / \mathrm{ml}$ which were stored at $-80^{\circ} \mathrm{C}$. Ionomycin was kept as a $4 \mathrm{mM}$ solution in DMSO and stored at $-80^{\circ} \mathrm{C}$.

Antibodies used. The generation and characterization of murine monoclonal antibodies anti-Mol (anti-CD11b, IgG2a, clone 44) (39), anti-Mo1 (anti-CD11b, IgM, clone 17) (40), anti-Mo2 (anti-CD14, IgG2b, clone 26) (41), anti-Mo3e (IgM, clone 109) (36), anti-I3 (anti-Ia, IgG2a, clone 9-49) (42), and anti- $\beta_{2} \mathrm{M}$ (anti-HLA-A, B, C, IgG2b, clone 88) (43) have previously been described. The anti- $\beta_{2} \mathrm{M}$ was a generous gift of Dr. Lee Nadler of the Dana-Farber Cancer Institute (Boston, MA). Monoclonal antibodies were diluted 1:100 in Dulbecco's phosphate-buffered salinc (DPBS) with $1 \%$ BSA and $0.1 \%$ glucose (radioimmunoassay buffer (RIA-buffer)). Polyclonal ${ }^{125}$ I-labeled sheep $\mathrm{F}\left(\mathrm{ab}^{\prime}\right)_{2}$ anti-mouse immunoglobulin fragments $\left({ }^{125} \mathrm{I}\right.$-SAM $\mathrm{Ig}$ ) were purchased from DuPont, NEN Products (NEX-162, Boston, MA) and used after dilution in RIA-buffer to a final stock concentration of $2.5 \times 10^{6} \mathrm{cpm} / \mathrm{ml}$. 
Endothelial cell cultures. HUVEC were harvested from normal term delivery human umbilical cords by the method of Gimbrone et al. (44) and were serially propogated according to the protocol of Maciag et al. (45) as modified by Weiss and Regiani (46) in which endothelial cells were cultured in $20 \%$ pooled human serum. Except where indicated, HUVEC were propogated in Costar (Cambridge, MA) 24-well plates which had been precoated with a $0.2 \%$ gelatin solution. For the majority of experiments, primary and first-passage cultures were employed. In selected experiments, multiply-passaged cells were used (up to the sixth passage). At the time of passage, HUVEC monolayers were disrupted into single cell suspensions using trypsin-EDTA and then seeded onto fresh gelatin-coated plates. Cultures were fed three times weekly (complete medium change) with growth medium consisting of M199 containing 20\% pooled human serum, $100 \mathrm{u} / \mathrm{ml}$ penicillin, $100 \mathrm{u} / \mathrm{ml}$ streptomycin, $2.5 \mu \mathrm{g} / \mathrm{ml}$ amphotericin B, and $150 \mu \mathrm{g} / \mathrm{ml} \mathrm{ECGS.}$

When confluent (4-6 days after seeding), 2.0- $\mathrm{cm}^{2}$ HUVEC monolayer cultures containing $0.5 \mathrm{ml}$ of growth medium were stimulated by the addition of various soluble factors in 5- to $100-\mu 1$ volumes. For additives initially dissolved in DMSO, ethanol, or methanol, the final solvent concentration did not exceed $0.5,0.2$, or $0.3 \%$, respectively. In most experiments, HUVEC were subsequently cultured for an additional $24 \mathrm{hr}$ at $37^{\circ} \mathrm{C}$ in a humidified atmosphere of $5 \% \mathrm{CO}_{2}$ in air prior to RIA. In other experiments, HUVEC were cultured for varying lengths of time up to $120 \mathrm{hr}$.

In selected experiments, HUVEC were seeded in gelatin-coated 35-mm culture dishes (Falcon Plastic Division of Becton-Dickinson Laboratories, Lincoln Park, $\mathrm{NJ}$ ), and when confluent, cultured in the presence of stimulating factors as indicated above.

Monocyte-conditioned medium. Peripheral blood mononuclear cells (PBMC) were isolated by Histopaque-1077 density gradient centrifugation (47) of heparin-anticoagulated blood $(4 \mathrm{u} / \mathrm{ml}$ ) from healthy volunteer donors. Monocyte-rich adherent cells were obtained by incubating PBMC in 1640-AS (RPMI 1640 medium supplemented with $10 \%$ autologous serum) on 100-mm plastic culture dishes (Falcon Plastics, Oxnard, CA) pretreated with autologous serum (48). After $60 \mathrm{~min}$ at $37^{\circ} \mathrm{C}$, nonadherent PBMC were aspirated off, and the plates were washed with five changes of $37^{\circ} \mathrm{C} \mathrm{HBSS}$ ( $5 \mathrm{ml}$ each wash). After washing, the monocyte cultures were fed with $5 \mathrm{ml}$ of 1640 AS and cultured with $50 \mathrm{ng} / \mathrm{ml}$ LPS for $72 \mathrm{hr}$ at $37^{\circ} \mathrm{C}$ in a humidified atmosphere of $5 \% \mathrm{CO}_{2}$ in air. The supernatant medium was then harvested by aspiration, filtered $(0.22 \mu \mathrm{m})$, and stored at $-80^{\circ} \mathrm{C}$ until use.

Radioimmunoassay. In experiments designed to measure monoclonal antibody binding to $2.0-\mathrm{cm}^{2}$ monolayer cultures of HUVEC, an indirect RIA was employed (all steps carried out at $4^{\circ} \mathrm{C}$ ): The medium was removed sequentially from each well and $200 \mu \mathrm{l}$ of a 1:100 (saturating) dilution of the primary mouse monoclonal antibody was added to each well and allowed to incubate for $30 \mathrm{~min}$. For each experimental antibody an isotype-identical negative control monoclonal antibody was run in parallel as a measure of nonspecific antibody binding. The primary antibody was then removed and each well was sequentially rinsed twice with $300 \mu$ l of RIA buffer prior to the addition of $200 \mu \mathrm{l}$ of ${ }^{125} \mathrm{I}-\mathrm{SAM}$ Ig containing $5 \times 10^{5} \mathrm{cpm}$. After a second 30 -min incubation, ${ }^{125}$ I-SAM Ig was removed and each well was rinsed three times with $300 \mu$ l RIA-buffer solution. After the last wash the HUVEC cultures were solubilized by the addition of $400 \mu$ l DPBS containing 1\% Nonidet P-40 (NP-40) and al- 
lowed to incubate for $1 \mathrm{hr}$ at room temperature. The cell lysates were then transferred to $8 \times 75-\mathrm{mm}$ plastic tubes for counting in a TM-Analytic Gamma Trac 1191 gamma scintillation counter (Elk Grove Village, IL). Specific ${ }^{125}$ I-SAM Ig binding was calculated by subtracting the mean counts per minute (cpm) of triplicate cultures exposed to the negative control monoclonal antibody (generally IgM anti-Mol) from that of triplicate cultures exposed to the experimental antibody (generally IgM anti-Mo3e). In selected experiments, HUVEC monolayers were fixed prior to RIA according to the following protocol: medium was removed and the monolayers were incubated in $300 \mu \mathrm{l}$ of PBS containing $10 \%$ formaldehyde for $10 \mathrm{~min}$ at $4^{\circ} \mathrm{C}$. The monolayers were washed three times by the addition of $300 \mu \mathrm{l}$ PBS and then incubated in $300 \mu \mathrm{l}$ of a 1:1 solution of methanol: $3 \% \mathrm{H}_{2} \mathrm{O}_{2}$ in water for $10 \mathrm{~min}$ at $4^{\circ} \mathrm{C}$. After three additional washes in PBS, the cells were subjected to RIA as above.

Immunoperoxidase assay. Immunocytochemical localization of antibody binding was carried out by a modification of the immunopcroxidase avidin-biotin complex technique ( $\mathrm{ABC}$ method) described by $\mathrm{Hsu}$ et al. (49) using a Vectastain $\mathrm{ABC}$ kit (mouse IgM No. PK-4010) purchased from Vector Labs (Burlington, CA). All steps were carried out at room temperature. Confluent monolayers of HUVEC grown on $35-\mathrm{mm}$ culture dishes were incubated in growth medium containing $50 \mathrm{ng} / \mathrm{ml} \mathrm{PMA}$ or control medium for $24 \mathrm{hr}$ prior to fixation as detailed in the preceding paragraph. The plates were washed three times with $2 \mathrm{ml}$ of PBS and then incubated for $10 \mathrm{~min}$ in $2 \mathrm{ml}$ of PBS containing 6\% normal goat serum (NGS) and 4\% BSA. The monolayers were then exposed to $750 \mu \mathrm{l}$ of the primary monoclonal antibodies (diluted 1: 100 in PBS containing $1 \%$ NGS and 4\% BSA) for 30 min, washed three times in PBS, and then exposed to $750 \mu \mathrm{l}$ of the biotinylated goat anti-mouse IgM antibody (diluted 1:200 in PBS containing 1\% NGS and 4\% BSA) for $30 \mathrm{~min}$. After an additional three washes in PBS, $750 \mu 1$ of ABC reagent was then added to each plate. The plates were again incubated for $30 \mathrm{~min}$, washed twice in PBS, and then exposed to $0.04 \%$ diaminobenzidine in PBS for 10 min. After two distilled $\mathrm{H}_{2} \mathrm{O}$ rinses, the plates were counterstained with hematoxylin and examined directly using an American Optical OneTwenty microscope.

\section{RESULTS}

As shown in Table 1, exposure of primary cultures of HUVEC to PMA $(50 \mathrm{ng} / \mathrm{ml}$ for $24 \mathrm{hr}$ at $37^{\circ} \mathrm{C}$ ) induced the expression of Mo3e as detected in a RIA mcasuring the binding of anti-Mo3e monoclonal antibody to monolayers of PMA-stimulated and unstimulated HUVEC. Surface Mo3e expression by unstimulated HUVEC (after subtraction of background antibody binding) was negative. To exclude the possibility that this increase in surface Mo3e was a manifestation of a generalized upmodulation of HUVEC plasma membrane components, we examined the binding of other monoclonal reagents specific for class I and II histocompatibility antigens $\left(\beta_{2} \mathrm{M}\right.$ and Ia, respectively), as well as selected isotype identical control reagents (antiMo1 and anti-Mo2) that identify myelomonocytic antigens not expressed by endothelial cells (50-52). It can be seen that culture of HUVEC in media containing PMA did not affect the surface expression of class I or II histocompatibility antigens. Moreover, the increase in anti-Mo3e antibody binding to PMA-treated cells was not a consequence of an increase in the level of nonspecific antibody binding (as would be 
TABLE 1

Selective Surface Expression of Mo3e Antigen by PMA-stimulated HUVEC Monolayers ${ }^{a}$

\begin{tabular}{|c|c|c|}
\hline \multirow{2}{*}{$\begin{array}{c}\text { Monoclonal } \\
\text { antibody (isotype) }\end{array}$} & \multicolumn{2}{|c|}{${ }^{125}$ I-SAM Ig binding (mean cpm \pm SD) } \\
\hline & PMA-stimulated & Unstimulated \\
\hline \multicolumn{3}{|l|}{ Experimental } \\
\hline Anti-Mo3e (IgM) & $4,372 \pm 40^{b}(3,285)^{c}$ & $1,179 \pm 118(134)$ \\
\hline Anti- $\beta_{2} M(\operatorname{IgG} 2 \mathrm{~b})$ & $14,162 \pm 443(12,938)$ & $14,133 \pm 532(12,696)$ \\
\hline Anti-I3 (IgG2a) & $1,919 \pm 392(1,013)$ & $1,912 \pm 155(913)$ \\
\hline \multicolumn{3}{|l|}{ Control } \\
\hline Anti-Mol (IgM) & $1,087 \pm 207$ & $1,045 \pm 78$ \\
\hline Anti-Mol (IgG2a) & $906 \pm 133$ & $999 \pm 87$ \\
\hline Anti-Mo2 (IgG2b) & $1,224 \pm 96$ & $1,437 \pm 43$ \\
\hline RIA Buffer & $515 \pm 6$ & $538 \pm 46$ \\
\hline
\end{tabular}

${ }^{a}$ HUVEC monolayers $\left(2.0 \mathrm{~cm}^{2}\right.$, primary cultures) were cultured in medium containing either PMA (50 $\mathrm{ng} / \mathrm{ml})$ or an equivalent amount of DMSO diluent $\left(0.1 \%\right.$, unstimulated) for $24 \mathrm{hr}$ at $37^{\circ} \mathrm{C}$ prior to RIA as described under Materials and Methods.

${ }^{b}$ Mean cpm ( ${ }^{125} \mathrm{I}-\mathrm{SAM}-\mathrm{Ig}$ bound) $\pm \mathrm{SD}$ of triplicate determinations.

${ }^{c}$ Numbers in parentheses indicate specific ${ }^{125}$ I-SAM Ig binding: mean ${ }^{125}$ I-SAM Ig bound to monolayers exposed to experimental antibodies minus mean ${ }^{125} \mathrm{I}$-SAM Ig bound to monolayers exposed to isotypeidentical control antibodies.

detected by an increase in the binding of anti-Mol and anti-Mo2 negative control antibodies). In addition, there was no significant difference in the number of viable endothelial cells per monolayer in PMA-stimulated and unstimulated HUVEC at the time of the assay (data not shown), excluding the possibility that such a numerical difference could account for the results observed. On the basis of these results (reproducible in over 80 experiments), we conclude that unstimulated HUVEC express negligible quantities of surface Mo3e but that exposure to PMA induces the selective acquisition of surface Mo3e expression not only by primary cultures of HUVEC but also by multiply passaged cells (up to six passages; data not shown).

By surface immunofluoresence analysis of unfixed PMA-stimulated HUVEC and by immunoperoxidase staining of formalin-fixed cells (data not shown), a diffuse pattern of Mo3e expression was observed, indicating that Mo3e expression by HUVEC is a feature shared by the vast majority of stimulated HUVEC.

As seen in Figs. 1 and 2, the magnitude of surface Mo3e expression by PMA-stimulated HUVEC was directly related to the concentration of PMA and to the duration of stimulation. Peak Mo3e expression was observed at PMA concentrations exceeding $25 \mathrm{ng} / \mathrm{ml}$ (range $3-200 \mathrm{ng} / \mathrm{ml}$ ) and after $14 \mathrm{hr}$ of culture in media containing PMA (range 4-120 hr).

Since PMA is a stimulus of surface Mo3e expression by HUVEC, we then evaluated the stimulatory capacity of other related compounds that are known to activate protein kinase $C$ in mammalian cells (reviewed in $(53,54)$ ). As shown in Fig. 3, two other biologically active phorbol compounds, $4 \beta \mathrm{PDD}$ and $4 \beta \mathrm{PDB}$, stimulated the expression of surface Mo3e as did the related diterpene compound MEZ (55). In contrast, the biologically inert $\alpha$ stereoisomer of $4 \beta \mathrm{PDD}$ and the parent alcohol $4 \beta$ - 


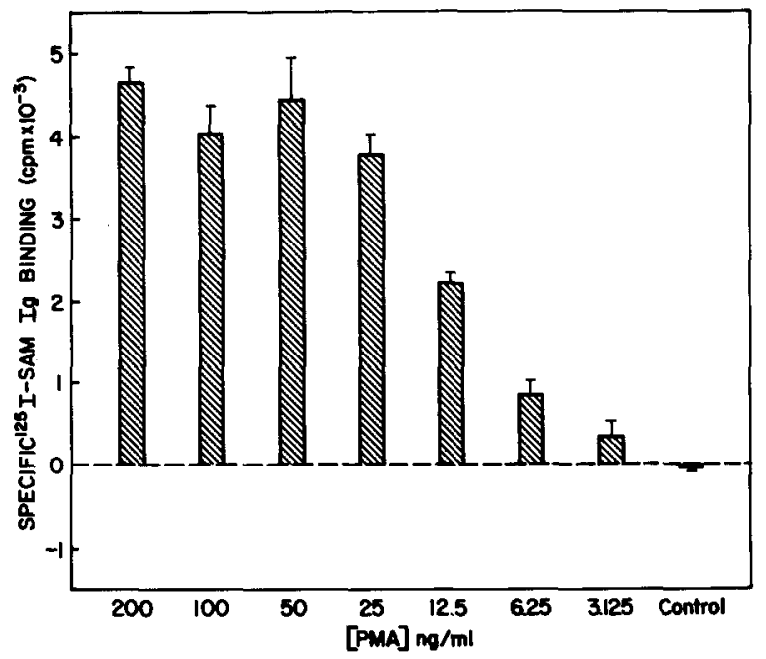

FIG. 1. Surface expression of Mo3e antigen as a function of PMA concentration. Triplicate $2.0-\mathrm{cm}^{2}$ (first passage) HUVEC monolayers were cultured for $24 \mathrm{hr}$ at $37^{\circ} \mathrm{C}$ in medium containing the indicated concentrations of PMA, or medium alone (control). The height of the bars represents specific surface expression of Mo3e as measured by specific ${ }^{125} \mathrm{I}-\mathrm{S} \Lambda \mathrm{M}$-Ig binding detected by $\mathrm{RI} \Lambda$ as described under Materials and Methods (mean cpm \pm SD). The subtracted nonspecific (anti-Mol) binding was 1436, 1792, $1868,1596,1501,1911,1918$, and 1666 (mean cpm, left to right). In control experiments (not shown), specific ${ }^{125}$ I-SAM-Ig hinding by cultures receiving DMSO diluent was indistinguishable from that of cultures to which no DMSO was added. The results of this experiment are representative of those seen in five similar experiments.

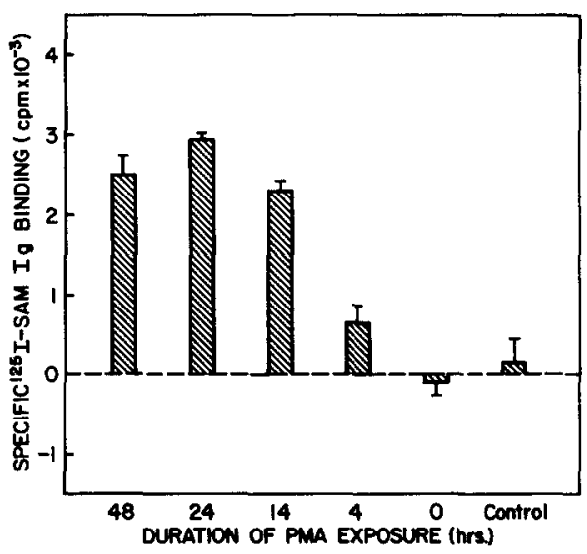

FIG. 2. Surface expression of Mo3e antigen as a function of the duration of PMA exposure. HUVEC (primary culture) monolayers $\left(2 \mathrm{~cm}^{2}\right)$ were cultured for $48 \mathrm{hr}$ at $37^{\circ} \mathrm{C}$; PMA (to make a final concentration of $50 \mathrm{ng} / \mathrm{ml}$ ) was added sequentially such that triplicate cultures were exposed to PMA for the indicated durations. In the "0-hr" duration cultures, PMA was added just prior to the RIA; "control" cultures received no PMA. As in Fig. 1, the height of the bars represents the mean specific ${ }^{125}$ I-SAM-Ig binding \pm SD. The subtracted nonspecific (anti-Mol) binding was 1455, 1746, 1713, 1596, 2459, and 2225 (mean cpm, left to right). As in Fig. 1, the addition of DMSO diluent alone had no effect on surface Mo3e expression. The results of this experiment are representative of those seen in three similar experiments. 


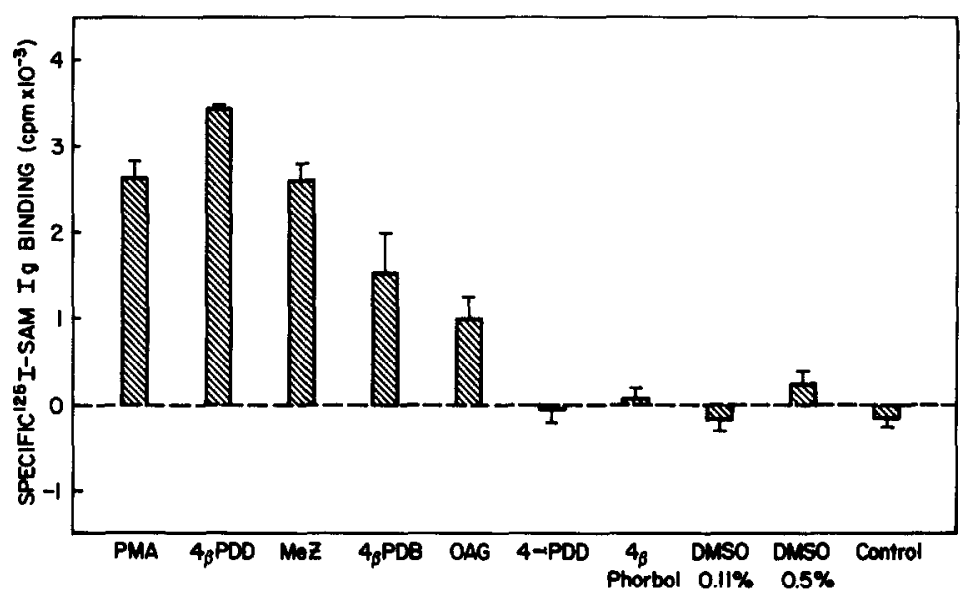

FIG. 3. Surface expression of Mo3e antigen stimulated by other phorbol compounds, mezerein, and OAG. Triplicate $2.0-\mathrm{cm}^{2} \mathrm{HUVEC}$ (first passage) monolayers were cultured for $24 \mathrm{hr}$ at $37^{\circ} \mathrm{C}$ in the presence of the compounds listed. PMA, $4 \beta \mathrm{PDD}, 4 \beta \mathrm{PDB}, 4 \alpha \mathrm{PDD}, 4 \beta$-phorbol, and mezerein were all added such that the final concentration of each was $81 \mathrm{n} M$ (equivalent to $50 \mathrm{ng} / \mathrm{ml}$ PMA; an appropriate control for the highest concentration of DMSO diluent to which the cells were exposed, $0.11 \%$, was included, as shown). As previously described (58), the OAG was added in 11 hourly doses to give a final concentration of $1 \mathrm{~m} M$ (OAG being rapidly degraded $(56,57)$ ). Parallel control cultures received DMSO to a final concentration of $0.5 \%$. Other control cultures received no additives. The height of the bars represents the mean specific ${ }^{125}$ I-SAM-Ig binding \pm the SD. Subtracted nonspecific (anti-Mol) binding was 1636, 1655, 1905, $1818,1403,1721,1651,1838,1350$, and 1672 (mean cpm, left to right). The results of this experiment are representative of those seen in three similar experiments.

phorbol were inactive in stimulating Mo3e expression. These observations suggested a relationship between the capacity of these agents to stimulate the expression of Mo3e and their reported activity in stimulating protein kinase $C$ activation $(53,54)$. This notion was further supported by the stimulatory effect of the cell-permeable diacylglycerol compound $O A G$ which can mimic the effect of endogenous 1,2-diacylglycerol in stimulating protein kinase $C$ activity $(56,57)$ (Fig. 3).

Because of reports demonstrating the synergistic effect of calcium ionophores and PMA in generating effector responses in other cellular systems (58-63), we then evaluated the combined stimulatory capacity of ionomycin and PMA to induce surface Mo3e expression by HUVEC. In Fig. 4, it can be seen that ionomycin alone at a concentration of $1 \mu M$ had a modest stimulatory effect that was additive to that of PMA at the submaximally stimulatory concentrations of $5-10 \mathrm{ng} / \mathrm{ml}$. In several experiments as represented by the data in Fig. 4, ionomycin had a synergistic effect with PMA at the maximally stimulatory concentrations of $25-50 \mathrm{ng} / \mathrm{ml}$. An increase in intracellular calcium induced by ionomycin may therefore promote surface Mo3e expression stimulated by PMA (53).

To determine if protein synthesis is required for the surface expression of Mo3e on HUVEC stimulated by PMA, we examined the effect of cycloheximide when added to HUVEC cultures at the start of their incubation with PMA. As shown in Fig. 5, cycloheximide at a concentration of $1 \mu \mathrm{g} / \mathrm{ml}$ inhibited the surface expression of Mo3e by approximately $80 \%$. This concentration of cycloheximide was noncytotoxic (as determined by trypan blue exclusion) and did not cause the detachment of PMA- 


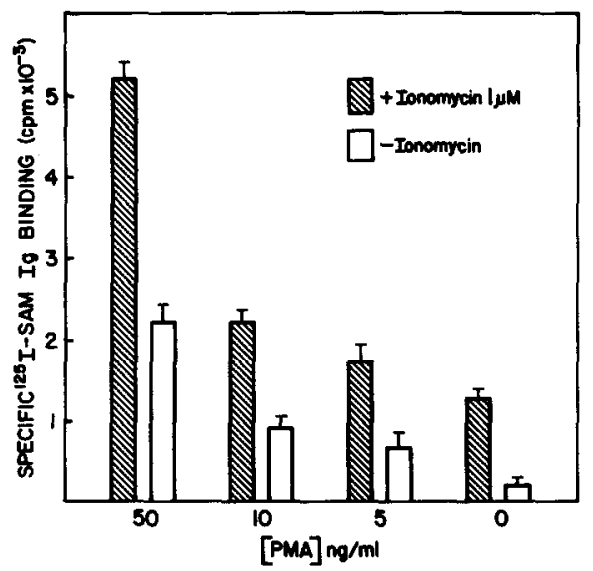

FIG. 4. PMA and ionomycin have additive or synergistic effects on surface Mo3e expression. Triplicate $2.0-\mathrm{cm}^{2} \mathrm{HUVEC}$ (primary culture) monolayers were cultured for $24 \mathrm{hr}$ at $37^{\circ} \mathrm{C}$ in medium containing the indicated concentrations of PMA, either in the presence or in the absence of $1 \mu M$ ionomycin. The height of the bars represents the mean specific ${ }^{125}$ I-SAM-Ig binding \pm the SD. Subtracted nonspecific (anti-Mol) binding was $1118,1102,1131,1400,1145,1543,1095$, and 1567 (mean cpm, left to right). The addition of DMSO diluent alone had no effect on surface Mo3e expression. The results of this experiment are representative of those seen in seven similar experiments.

stimulated cells from the monolayer substrate (as did concentrations exceeding $2 \mu \mathrm{g} /$ $\mathrm{ml}$ ). These data suggest a requirement for protein synthesis during induction of surface Mo3e expression stimulated by PMA.

Immunoperoxidase staining of formalin/methanol-fixed HUVEC for the expression of Mo3e demonstrated specific antibody binding to unstimulated HUVEC as well as to monolayers stimulated by PMA (data not shown). This suggested the possibility that while unstimulated HUVEC express little, if any, surface Mo3e (as determined by RIA of viable unfixed cells), they may contain a sequestered pool of cy-

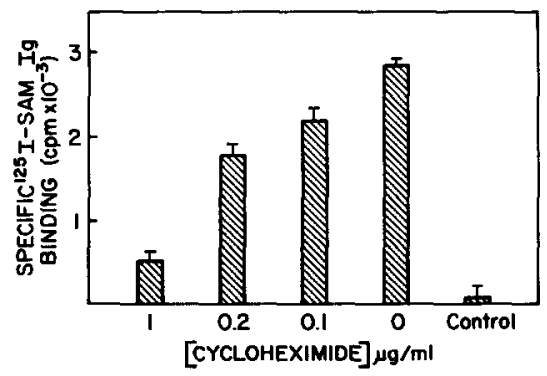

FIG. 5. Inhibition of surface Mo3e expression by cycloheximide. Triplicate $2.0-\mathrm{cm}^{2}$ HUVEC (first-passage) monolayers were cultured for $24 \mathrm{hr}$ at $37^{\circ} \mathrm{C}$ in medium containing $50 \mathrm{ng} / \mathrm{ml} \mathrm{PMA}$ and the indicated concentrations of cycloheximide. Control monolayers were cultured in the absence of both PMA and cycloheximide. The height of the bars represents the mean specific ${ }^{125}$ I-SAM-Ig binding \pm the SD. Subtracted nonspecific (anti-Mo1) binding was $763,742,816,1013$, and 1072 (mean cpm, left to right). At the concentrations of cycloheximide tested, HUVEC monolayers remained confluent and excluded trypan blue. The results of this experiment are representative of those seen in four similar experiments. 
TABLE 2

Detection of Mo3e Antigen in Formalin-Fixed, Unstimulated HUVEC ${ }^{a}$

\begin{tabular}{cccccc}
\hline & \multicolumn{4}{c}{ Specific ${ }^{125}$ I-SAM Ig binding (mean \pm SD) } \\
\cline { 2 - 3 } & \multicolumn{2}{c}{ Unfixed } & & \multicolumn{2}{c}{ Formalin-fixed } \\
\cline { 2 - 3 } Expt. No. & PMA-stimulated & Unstimulated & & PMA-stimulated & Unstimulated \\
\hline \multirow{2}{*}{1} & $3540 \pm 256^{h}$ & $447 \pm 50$ & & $2597 \pm 292$ & $2136 \pm 171$ \\
& $(1026)^{c}$ & $(1421)$ & & $(6586)$ & $(6731)$ \\
2 & $2130 \pm 78$ & $356 \pm 114$ & & $2172 \pm 168$ & $1394 \pm 402$ \\
3 & $(1172)$ & $(1527)$ & & $(6393)$ & $(6440)$ \\
& $3049 \pm 128$ & $417 \pm 132$ & & $2713 \pm 510$ & $1431 \pm 328$ \\
& $(901)$ & $(987)$ & & $(4876)$ & $(5042)$ \\
\hline
\end{tabular}

${ }^{a}$ HUVEC monolayers ( $2.0 \mathrm{~cm}^{2}$, primary cultures in Experiments 1 and 2; fifth-passage cultures in Experiment 3) were cultured in medium containing either PMA $(50 \mathrm{ng} / \mathrm{ml})$ or no additive (unstimulated) for 24 $\mathrm{hr}$ at $37^{\circ} \mathrm{C}$. Parallel triplicate monolayers were then either formalin-fixed (see Materials and Methods) or left unfixed prior to RIA for the expression of Mo3e (as measured by specific ${ }^{125}$ I-SAM Ig binding).

${ }^{b}$ Specific ${ }^{125}$ I-SAM Ig binding (mean cpm \pm SD of triplicate determinations).

${ }^{\circ}{ }^{125}$ I-SAM Ig binding (mean of triplicate determinations) to monolayers exposed to isotype-identical negative control reagent (anti-Mo1), i.e., background binding. In Experiments 1 and 2, ${ }^{125}$ I-SAM Ig binding to anti-Mo2-treated monolayers (as an additional IgM-negative control) was nearly identical to that shown for anti-Mol.

toplasmic antigen. This conclusion was supported by the results of quantitative RIA in which significant levels of specific anti-Mo3e binding to fixed, unstimulated HUVEC was detected (Table 2). The greater magnitude of specific anti-Mo3e binding to fixed PMA-stimulated cells over that bound to fixed unstimulated HUVEC may indicate the synthesis of new antigen in addition to that found in pre-existing cytoplasmic pools.

As indicated in Table 3, we evaluated the stimulatory activity of other soluble factors in addition to PMA that have been reported to either up-regulate endothelial cell and/or macrophage functional activity or to increase the surface expression of plasma membrane receptors and antigenic determinants: lymphokines and monokines (PHA-stimulated lymphocyte-conditioned media (PHA-LCM) (64), recombinant IFN- $\gamma(5,8-14,18)$, IL-2 (65), LPS-stimulated monocyte-conditioned media (I.PSMCM) (7), IL-1 (18, 19, 24-27), TNF $(19,22,23))$, bacterial cell wall products (LPS and MDP $(24,25,27,36)$ ), lectins (PHA (66) and Con-A (7)), drugs that raise the intracellular concentration of cyclic adenosine monophosphate (cyclic AMP) (cholera toxin, isoproterenol, theophylline, IBMX, and PGE-2 (67-70)), and heparin (endothelial cell growth stimulatory activity (71)). Whereas crude lymphokine and monokine supernatants, bacterial cell wall products, certain recombinant lymphokines, and monokines stimulated morphologic changes characteristic of those seen in HUVEC monolayers stimulated by PMA (Table 3), there was no reproducible parallel stimulation of surface Mo3e expression by these factors when tested over broad concentration ranges and at exposures lasting from 4 to $72 \mathrm{hr}$. The only exception was a variable degree of low magnitude surface Mo3e expression stimulated by either PHA or PHA-LCM. 
TABLE 3

Factors That Fail to Stimulate the Surface Expression of Mo3e by HUVEC

\begin{tabular}{|c|c|c|c|c|}
\hline Stimulus & $\begin{array}{l}\text { Concentration } \\
\text { range tested }\end{array}$ & $\begin{array}{l}\text { Duration }^{a} \\
\text { (hr) }\end{array}$ & $\begin{array}{l}\text { Morphologic } \\
\text { changes }^{b}\end{array}$ & $\begin{array}{c}\text { Experiments } \\
(N)^{c}\end{array}$ \\
\hline PHA-LCM ${ }^{d}$ & $5-20 \%$ & $4-72$ & ++ & 4 \\
\hline LPS-MCM & $1-10 \%$ & $24-72$ & ++ & 3 \\
\hline IL-1 & $0.5-20 \mathrm{u} / \mathrm{ml}$ & $24-72$ & + & 2 \\
\hline TNF & $10-1,000 \mathrm{u} / \mathrm{ml}$ & $4-120$ & +++ & 5 \\
\hline IFN- $\gamma$ & $10-1,000 \mu / \mathrm{ml}$ & $4-120$ & +++ & 7 \\
\hline IL-2 & $10-10,000 \mathrm{u} / \mathrm{ml}$ & $4-72$ & - & 4 \\
\hline E. coli LPS & $0.01-31 \mu \mathrm{g} / \mathrm{ml}$ & $4-72$ & + & 5 \\
\hline MDP & $0.1-10 \mu M$ & $4-72$ & ++ & 4 \\
\hline $\mathrm{PHA}^{d}$ & $0.5-250 \mu \mathrm{g} / \mathrm{ml}$ & 24 & ++ & 4 \\
\hline Con A & $0.05-50 \mu \mathrm{g} / \mathrm{ml}$ & 24 & \pm & 2 \\
\hline Cholera toxin & $1-100 \mathrm{ng} / \mathrm{ml}$ & $4-72$ & - & 7 \\
\hline Isoproterenol & $5-500 \mu M$ & $4-24$ & - & 3 \\
\hline $\mathrm{PGE}_{2}$ & $0.1-10 \mu M$ & $4-24$ & - & 4 \\
\hline Theophylline & $0.05-1.0 \mathrm{~m} M$ & $4-24$ & - & 3 \\
\hline IBMX & $0.05-1.0 \mathrm{mM}$ & $4-24$ & - & 4 \\
\hline Heparin & $3.75-60 \mathrm{u} / \mathrm{ml}$ & 24 & - & 2 \\
\hline
\end{tabular}

${ }^{a}$ Duration of culture period during which HUVEC monolayers were exposed to stimuli.

${ }^{b}$ Degree to which monolayer cells exhibited a "whorling" morphology: ranging from $(-)$, no shape changes observed, to $(+++)$ majority of monolayer cells exhibiting marked shape changes similar to that stimulated by PMA.

${ }^{c}$ Number of separate experiments performed.

${ }^{d}$ Poorly reproducible, low-level expression of surface Mo3e induced.

\section{DISCUSSION}

Based upon previous studies involving human mononuclear phagocytes, Mo3e is a protease-sensitive antigen $(\mathrm{p} 75,50)$ that is selectively expressed by human monocytes and myelomonocytic cell lines after exposure in vitro to soluble activating factors that include PMA and certain other biologically active phorbol compounds, bacterial LPS, and MDP (72). As shown in this report, the surface expression of Mo3e is also a feature characteristic of HUVEC stimulated by PMA and related compounds. Control experiments demonstrated that the acquisition of surface Mo3e expression was a selective response of PMA-stimulated HUVEC (the surface expression of HUVEC class I and class II histocompatibility antigens being unaltered) and was not due to an increase in nonspecific monoclonal antibody binding or a relative increase in the number of PMA-stimulated cells. The specificity of anti-Mo3e antibody for PMA-stimulated HUVEC (as opposed to small numbers of contaminating leukocytes) was documented by visual examination of monolayers stained by immunofluoresence and immunoperoxidase techniques which showed a homogeneous pattern of expression. Since HUVEC cultured in the absencc of PMA, like unstimulated human monocytes (36), express little if any detectable surface Mo3e, we suggest that Mo3e may represent an activation marker of human endothelial cells as well as monocytes. In support of this hypothesis are the observations of Hancock and Todd (manuscript in preparation) that demonstrate preferential expression of Mo3e by 
TABLE 4

Plasma Membrane-Associated Components of Endothelial Cells Whose Expression Is Inducible by Soluble Stimuli ${ }^{a}$

\begin{tabular}{|c|c|c|c|}
\hline Surface component & $\begin{array}{l}\text { Stimuli inducing } \\
\text { expression }\end{array}$ & $\begin{array}{l}\text { Distribution } \\
\text { among nonendothelial cells }{ }^{b}\end{array}$ & Reference(s) \\
\hline $\mathrm{H} 4 / 18(\mathrm{p} 100,120)^{\mathrm{c}}$ & IL-1. TNF, LPS ${ }^{d}$ & None known & (37) \\
\hline ICAM-1 $(\mathrm{p} 97)^{c}$ & $\mathrm{IL}-1, \mathrm{IFN}-\gamma, \mathrm{TNF}^{d}$ & $\begin{array}{l}\text { Lymphoid cells; tissue macrophages; } \\
\text { U-937 and HL-60 human cell } \\
\text { lines }\end{array}$ & $(18,19)$ \\
\hline $\begin{array}{l}\text { Class II MHC } \\
\text { determinants }\end{array}$ & IFN- $\gamma$, PHA $^{d}$ & $\begin{array}{l}\text { Broad distribution including B } \\
\text { lymphocytes, activated T } \\
\text { lymphocytes, mononuclear } \\
\text { phagocytes }\end{array}$ & $(14,66)$ \\
\hline Fc receptors & $\begin{array}{l}\text { Leukocyte lysates } \\
\text { CMV and } \\
\text { influenza virus } \\
\text { infection }^{d}\end{array}$ & $\begin{array}{l}\text { Broad distribution including } \\
\text { lymphoid cells, neutrophils, and } \\
\text { mononuclear phagocytes }\end{array}$ & (17) \\
\hline $\begin{array}{l}\text { Procoagulant } \\
\text { activity }\end{array}$ & IL-1, LPS, TNF ${ }^{d}$ & Monocytes and tissue macrophages & $(22-25)$ \\
\hline $\begin{array}{l}{ }^{a} \text { Selected list. } \\
{ }^{b} \text { Among human } c \\
{ }^{c} \text { Molecular weight } \\
{ }^{d} \text { HUVEC in vitro. }\end{array}$ & lypeptides. & & \\
\hline
\end{tabular}

macrophages within inflammatory foci (glomerulonephritis, allograft rejection, sarcoidosis, and appendicitis) of immunoperoxidase-stained frozen tissue sections. Among endothelial cells, capillary endothelium of normal ovary, lymph nodes, lung, and skin were weakly Mo3e positive but endothelial staining was more prominent in inflammatory specimens. Some Mo3e staining by "normal" macrophages and endothelial cells in these tissue specimens is consistent with our observation that there exists a sequestered pool of intracellular Mo3e detectable in fixed (permeabilized), unstimulated U-937 cells (73) and HUVEC (Table 2).

While a "physiological" stimulus of HUVEC Mo3e expression has not as yet been identified (Table 3), we suspect that expression of surface Mo3e by PMA-stimulated HUVEC is not an in vitro artifact. We base this conclusion on the selective stimula-

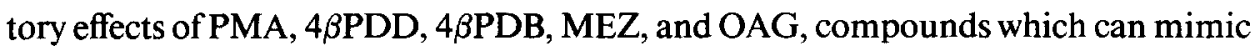
the effect of endogenous 1,2-diacylglycerol in activating protein kinase $C(53,54)$. The additive or synergistic effect of the calcium ionophore, ionomycin, and PMA suggests the additional contribution of intracellular calcium mobilization (59-63) to an activation process leading to surface Mo3e expression. These observations are therefore consistent with the notion that surface Mo3e expression by HUVEC is an effector response that depends upon protein kinase $\mathrm{C}$ activation and calcium mobilization stimulated by endogenous products of the phosphatidylinositol signal transduction pathway 1,2-diacylglycerol and inositol trisphosphate, respectively $(53,54)$. As demonstrated in other biological systems, these products are generated by phosphatidylinositol hydrolysis stimulated by receptor-mediated ligand binding $(53,54)$. 
The quest for a "natural" ligand that is stimulatory of Mo3e expression in HUVEC is still in progress.

As shown in Table 4, Mo3e expression by PMA-stimulated HUVEC is one of several plasma membrane phenotypic changes associated with exposure of HUVEC to soluble activating stimuli. Included among these changes is the expression of ICAM$1(18,19)$, a $97-\mathrm{kDa}$ adhesion-promoting molecule shared by human leukocytes ( $\mathrm{U}$ 937, HL-60) (18) and endothelial cells cultured in the presence of PMA or certain natural cellular products of stimulated leukocytes (IL-1, IFN- $\gamma$, or TNF) (19). Its molecular weight and expression by lymphocytes clearly distinguish ICAM-1 from Mo3e (p75, 50) (72). Also distinct from Mo3e is the H4/18 antigen (p100, 120) (37) which is a transient feature of HUVEC exposed to IL-1 or TNF (37): its expression by HUVEC as measured by RIA reaches a peak at 3-6 hr of culture and then declines to undetectable baseline levels (37). Other surface components whose activity or density is up-regulated by exposure to activating stimuli include endothelial cell procoagulant activity (stimulated in HUVEC by IL-1, TNF, or LPS (22-25, 27), class II histocompatibility antigens (stimulated in HUVEC by PHA and IFN- $\gamma(14,66)$ ), and $\mathrm{Fc}$ receptors (stimulated in bovine pulmonary endothelial cells by leukocyte-derived lysates or infection with CMV or influenza virus (17)).

The physiological significance of Mo3e expression by PMA-stimulated HUVEC is as yet unknown. We have previously reported that anti-Mo3e monoclonal antibody blocks the response of human monocytes to migration inhibitory factor (MIF), suggesting that Mo3e contributes to MIF responsiveness (74). Whether Mo3e itself represents the surface receptor for MIF remains to be determined in direct ligand binding assays. What role Mo3e plays in the functional activity of endothelial cells is open to speculation but its capacity to promote the binding of MIF ligand by endothelial cells will be assessed.

\section{ACKNOWLEDGMENTS}

The authors gratefully acknowledge the contribution of the following individuals and institutions: Dr. Lee Nadler (Dana-Farber Cancer Institute) for his gift of anti- $\beta_{2} M$ antibody, Dr. Sidney Pestka (Roche Institute of Molecular Biology) for his gift of IFN- $\gamma$, the Cetus Corporation for its gift of TNF and IL-2, Dr. Ricardo Lloyd (University of Michigan) for his advice on immunoperoxidase staining, and Mr. Dennis Dicks for his secretarial assistance. This work was supported in part by National Institute of Health Grants CA39064, CA42246, and HL28024.

\section{REFERENCES}

1. Nathan, C. F., Murray, H. W. and Cohn, Z. A., N. Engl. J. Med. 303, 622, 1980.

2. Hausmann, K., Wulfhekel, U., Dullmann, J., and Kuse, R., Blut 32, 289, 1976.

3. Hirschberg, H., Bergh, O. J., and Thorsby, E., J. Exp. Med. 152, 249s, 1980.

4. Wagner, C. R., Vetto, R. M., and Burger, D. R., Immunobiology 168, 453, 1984.

5. Geppert, T. D., and Lipsky, P. E., J. Immunol. 135, 3750, 1985.

6. Unanue, E. R., Beller, D. I., Lu, C. Y., and Allen, P. M., J. Immunol. 132, 1, 1984.

7. Dinarello, C. A., Rev. Infect. Dis. 6, 51, 1984.

8. Minssec, P., Cavender, D., and Ziff, M., J. Immunol. 136, 2486, 1986.

9. Miossec, P., and Ziff, M., J. Immunol. 137, 2848, 1986.

10. Basham, T. Y., and Merigan, T. C., J. Immunol. 130, 1492, 1983.

11. Kelley, V. E., Fiers, W., and Strom, T. B., J. Immunol. 132, $240,1984$.

12. Sztein, M. B., Steeg, P. S., Johnson, H. M., and Oppenheim, J. J., J. Clin. Invest. 73, 556, 1984.

13. Becker, S., J. Immunol. 132, 1249, 1984. 
14. Pober, J. S., Gimbrone, M. A., Jr., Cotran, R. S., Reiss, C. S., Burakoff, S. J., Fiers, W., and Ault, K. A., J. Exp. Med. 157, 1339, 1983.

15. Guyre, P. M., Morganelli, P. M., and Miller, R., J. Clin. Invest. 72, 393, 1983.

16. Perussia, B., Dayton, E. T., Lazarus, R., Fanning, V., and Trinchieri, G., J. Exp. Med. 158, 1092, 1983.

17. Ryan, U. S., Schultz, D. R., and Ryan, J. W., Science 214, 557, 1981.

18. Dustin, M. L., Rothlein, R., Bhan, A. K., Dinarello, C. A., and Springer, T. A., I. Immunol 137, 245, 1986.

19. Pober, J. S., Gimbrone, M. A., Jr., Lapierre, L. A., Mendrick, D. L., Fiers, W., Rothlein, R., and Springer, T. A., J. Immunol. 137, 1893, 1986.

20. Edwards, R. L., Rickles, F. R., and Bobrove, A. M., Blood 54, 359, 1979.

21. Helin, H., and Edgington, T. S., J. Exp. Med. 158, 962, 1983.

22. Bevilacqua, M. P., Pober, J. S., Majeau, G. R., Fiers, W., Cotran, R. S., and Gimbrone, M. A., Jr., Proc. Natl. Acad. Sci. USA 83, 4533, 1986.

23. Nawroth, P. P., and Stern, D. M., J. Exp. Med. 163, 740, 1986.

24. Bevilacqua, M. P., Pober, J. S., Majeau, G. R., Cotran, R. S., and Gimbrone, M. A., Jr., J. Exp. Med. 160, 618, 1984.

25. Colucci, M., Baiconi, G., Lorenzet, R., Pietra, A., Locati, D., Donati, M. B., and Semeraro, M., $J$. Clin. Invest. 71, 1893, 1983.

26. Bevilacqua, M. P., Pober, J. S., Wheeler, M. E., Cotran, R. S., and Gimbrone, M. A., Jr., J. Clin. Invest. 76, 2003, 1985.

27. Bevilacqua, M. P., Pober, J. S., Wheeler, M. E., Cotran, R. S., and Gimbrone, M. A., Jr., Amer. J. Pathol. 121, 394, 1985.

28. Taniyama, T., and Tokunaga, T., J. Immunol. 131, 1032, 1983.

29. Akagawa, K. S., and Tokunaga, T., Microbiol. Immunol. 26, 831, 1982.

30. Gordon, S., and Hirsch, S., Adv. Exp. Med. Biol. 155, 391, 1982.

31. Fox, B. A., and Petty, H. R., Mol. Immunol. 21, 681, 1984.

32. Koestler, T. P., Badger, A. M., Rieman, D. J., Greig, R., and Poste, G., Cell. Immunol. 96, 113, 1985.

33. Koestler, T. P., Rieman, D., Muirhead, K., Greig, R. G., and Poste, G., Proc. Natl. Acad. Sci. USA 81, 4505, 1984.

34. Ewan, V. A., Cieplinski, W., Hancock, W. W., Goldschneider, I., Boyd, A. W., and Rickles, F. R., J. Immunol. 136, 2408, 1986.

35. Hancock, W. W., Rickles, F. R., Ewan, V. A., and Atkins, R. C., J. Immunol. 136, 2416, 1986.

36. Todd, R. F., III, Alvarez, P. A., Brott, D. A., and Liu, D. Y., J. Immunol. 135, 3869, 1985.

37. Pober, J. S., Bevilacqua, M. P., Mendrick, D. L., Lapierre, L. A., Fiers, W., and Gimbrone, M. A., Jr., J. Immunol. 136, $1680,1986$.

38. Cotran, R. S., Gimbrone, M. A., Jr., Bevilacqua, M. P., Mendrick, D. L., and Pober, J. S., J. Exp. Med. 164, 661, 1986.

39. Arnaout, M. A., Todd, R. F., III, Dana, N., Melamed, J., Schlossman, S. F., and Colten, H. R., J. Clin. Invest. 72, 171, 1983.

40. Todd, R. F., III, Bahn, A. K., Kabawat, S. E., and Schlossman, S. F., In "Leukocyte Typing" (A. Bernard, L. Boumsell, J. Dausset, C. Milstein, and S. F. Schlossman, Eds.), pp. 424-433. SpringerVerlag, New York, 1984.

41. Todd, R. F., III, van Agthoven, A., Schlossman, S. F., and Terhorst, C., Hybridoma 1, 329, 1982.

42. Todd, R. F., III, Meuer, S. C., Romain, R. L., and Schlossman, S. F., Hum. Immunol. 10, 23, 1984.

43. LeClair, K., van Agthoven, A., and Terhorst, C., J. Immunol. Methods 41, 137, 1981.

44. Gimbrone, M. A., In "Progress in Hemostasis and Thrombosis" (T. H. Spaet, Ed.), pp. 1-28. Grune \& Stratton, New York, 1976.

45. Maciag, T., Hoover, G. A., Stemerman, M. B., and Weinstein, R., J. Cell Biol. 91, 420, 1981.

46. Weiss, S. J., and Regiani, S., J. Clin. Invest. 73, 1297, 1984.

47. Boyum, A., Scand. J. Clin. Invest. 21(Suppl. 97), 77, 1968.

48. Fischer, D. G., Hubbard, W. J., and Koren, H. S., Cell. Immunol. 58, 426, 1981.

49. Hsu, S. M., Raine, L., and Fanger, H., J. Histochem. Cytochem. 29, 577, 1981.

50. Eddy, A., Newman, S. L., Cosio, F., LeBien, T., and Michael, A., Clin. Immunol. Immunopathol. 31, $371,1984$. 
51. Petranyi, G. G., Busch, G., Milford, E., Todd, R. F., III, Griffin, J., Reinherz, E., Terhorst, C., Schlossman, S. F., and Carpenter, C., In "Leukocyte Typing" (A. Bernard, L. Boumsell, J. Dausset, C. Milstein, and S. F. Schlossman, Eds.), p. 686. Springer-Verlag, New York, 1984.

52. Hancock, W. W., Kraft, N., and Atkins, R. C., In "I eukocyte Typing" (A. Bernard, L. Boumsell, J. Dausset, C. Milstein, and S. F. Schlossman, Eds.), pp. 493-499. Springer-Verlag, New York, 1984.

53. Nishizuka, Y., Nature (London) 308, 603, 1984.

54. Nishizuka, Y., Science 233, 305, 1986.

55. Miyake, R., Tanake, T., Tsuda, T., Kaibuchi, K., Kikkawa, U., and Nishizuka, Y., Biochem. Biophys. Res. Commun. 121, 649, 1984.

56. Ebeling, J. G., Vandenbark, G. R., Kuhn, L. J., Ganong, B. R., Bell, R. M., and Niedel, J. E., Proc. Natl. Acad. Sci. USA 82, 815, 1985.

57. Davis, R. J., Ganong, B. R., Bell, R. M., and Czech, M. P., J. Biol. Chem. 260, 1562, 1984.

58. Todd, R. F., III, Bury, M. J., Alverez, P. A., Brott, D. A., and Liu, D. Y., Blood 68, 1154, 1986.

59. Truneh, A., Albert, F., Golstein, P., Schmitt-Verhulst, A. M., Nature (London) 313, 318, 1985.

60. Isakov, N., and Altman, A., J. Immunol. 135, 3674, 1985.

61. Clevers, H. C., Versteegen, J. M. T., Logtenberg, T., Gmelig-Meyling, J., and Ballieux, R. E., J. Immunol. 135, 3827, 1985.

62. Smith, B. M., Sturm, R. J., and Carchman, R. A., Cancer Res. 43, 3385, 1983.

63. Somers, S. D., Weiel, J. E., Hamilton, T. A., and Adams, D. O., J. Immunol. 136, 4199, 1986.

64. Todd, R. F., III, Griffin, J. D., Ritz, J., Nadler, L. M., Abrams, T., and Schlossman, S. F., Leuk. Res. $5,491,1981$.

65. Herrmann, F., Cannistra, S. A., Levine, H., and Griffin, J. D., J. Exp. Med. 162, 1111, 1985.

66. Pober, J. S., and Gimbrone, M. A., Jr., Proc. Natl. Acad. Sci. USA 79, 6641, 1982.

67. Chaplinski, T. J., and Niedel, J. E., J. Clin. Invest. 70, 953, 1982.

68. Chaplinski, T. J., and Niedel, J. E., J. Leukocyte Biol. 39, 323, 1986.

69. Vogel, S. N., Weedon, L. L., Oppenheim, J. J., and Rosenstreich, D. L., J. Immunol. 126, 441, 1981.

70. Todd, R. F., III, Bury, M. J., and Liu, D. Y., J. Leuk. Biol. 41, 492, 1987.

71. Thornton, S. C., Mueller, S. N., and Levine, E. M., Nature (London) 222, 623, 1983.

72. Todd, R. F., III, and Liu, D. Y., Fed. Proc. 45, 2829, 1986.

73. Todd, R. F., III, Tripp, L. R., Adams, M. D., Ferrer, T. J., and Liu, D. Y., Clin. Res. 35, 467, 1987.

74. Liu, D., and Todd, R. F., III, J. Immunol. 137, 448, 1986. 